\title{
THE USE OF CRONOID-CONDYLAR INDEX IN DIAGNOSIS OF ELONGATED CORONOID PROCESS
}

\author{
Ahmed S. Naguib* and Rafic R. Bedier*
}

\begin{abstract}
Purpose: the aim of this study was to define the role of coronoid condylar index (CCI) in diagnosis of elongated coronoid process.

Patients and Methods: Eight patients with unilateral coronoid hyperplasia were included in this study, six patients were males and two patients were females, their ages ranged from 19-28years with a mean of 23.5 years. All patients were evaluated both clinically (through detection of range of mouth opening, range of mandibular deviation towards the affected side, presence of palpable crepitation or audible grating in the TMJ and finally vision of movement of the coronoid process in the infratemporal fossa during mouth opening ) and radiographically (from the lateral projection three dimensional computerized tomography of the lower jaw).
\end{abstract}

Results: regarding to the mouth opening, the mean of mouth opening for all patients was $25.3 \mathrm{~mm}$. the mean of deviation of the mandible towards the affected side was $3.5 \mathrm{~mm}$. Palpable crepitation and audible grating of the temporomandibular joint had been detected only in three cases. Vision of the coronoid process movement in the infratemporal fossa had been detected only in four cases, particularly during mouth opening. Radiographic evaluation revealed, the mean of the coronoid condylar index (CCI) to all the examined patients was $1.22 \mathrm{~mm}$.

Conclusion: The CCI is considered as simple and rapid method for determination of any discrepancy in both coronoid and condylar processes of the lower jaw.

\section{INTRODUCTION}

Coronoid process enlargement was discovered firstly by Langenbeck in 1953. (1) This pathology is rare and its etiology had not explained clearly uptill now and it is defined as abnormal triangular elongation of the coronoid process which consists of normal bone architecture. ${ }^{(2)}$ Although a number of theories had been proposed such as: 1) increased temporalis activity which may occurs due to temporomandibular joint affection, 2) endocrinal stimulus initiated at puberty, 3) trauma may be proposed as a reason for coronoid hyperplasia, although this seems to be less important. Also a

\footnotetext{
* Ass. Professor, Oral and Maxillofacial Surgery Dept., Faculty of Dentistry, Tanta University.
} 
syndromic relationship may exist in trismus-Pseudo camptodactyly syndrome. ${ }^{(3)}$

It was found that, the coronoid process hyperplasia most commonly affects the young males more than females. ${ }^{(3)}$

Coronoid process hyperplasia may occurs unilaterally but in most patients it occurs bilaterally. ${ }^{(4)}$

The elongated coronoid process may leads to occurrence of painless mechanical restriction of the mouth opening, which occurs due to impingement of the elongated coronoid process against the posterior surface of the body of the zygomatic bone and the medial surface of the zygomatic arch. ${ }^{(5)}$

Coronoid hyperplasia may be observed in many conditions such as oral submucous fibrosis and temporomandibular joint ankylosis. Also coronoid hyperplasia may occur as an isolated condition. ${ }^{(6)}$

The use of preoperative panographic examination and computed tomography are considered as golden tools to reach to the correct diagnosis. ${ }^{(7)}$

The radiographic image given by panographic examination often shows the degree of coronoid process enlargement, while the computed axial tomography demonstrates its relationship with the zygomatic arch. ${ }^{(8)}$

\section{Aim of the study}

The purpose of this study was to define the role of the coronoid-condylar index (CCI) in diagnosis of the elongated coronoid process.

\section{MATERIALS AND METHODS}

This study was conducted on eight patients, (six males and two females) who sought treatment at the Department of Oral and Maxillofacial Surgery, Faculty of Dentistry, Tanta University.

All patients who were included in this study were suffering from limitation in mouth opening range due to presence of unilateral coronoid hyperplasia.
The age of the patients ranged from 19-28 years with a mean of 23.5 years.

An approval of the trust ethical committee was obtained, together with a written informed consent from all patients. All cases were diagnosed on the basis of both clinical and radiographic findings as follow:

\section{I: clinical examination:}

Clinical examination of all included patients was achieved through determination of:

1. The range of mouth opening (in $\mathrm{mm}$ ).

2. Range of deviation of the mandible towards the affected side on the maximum opening, according to Stegenga et. al (1993). ${ }^{(9)}$

3. Presence of palpable crepitation.

4. Presence of audible grating.

5. Presence of visible movement of the enlarged coronoid process in the infratemporal fossa, particularly during mouth opening.

\section{II: Radiographic examination:}

The performed clinical diagnosis of enlarged coronoid process was verified by performing axial, coronal and three dimensional computerized tomograms in order to evaluate properly the geometry of the ramus of the lower Jaw and to accurately visualize the relation between the osseous structures, such as the zygomatic bone and the coronoid process. Also C.T. scanning with an open mouth can prove the exact location of impingement.

Determination of the height of the coronoid process and condylar process:

From the lateral projection three dimensional computerized tomograms of the lower jaw, the following lines and points can be actually determined Fig (I):

1- Line tangent to the mandibular angle and lower margin of the mandible in the mental region. (A) 


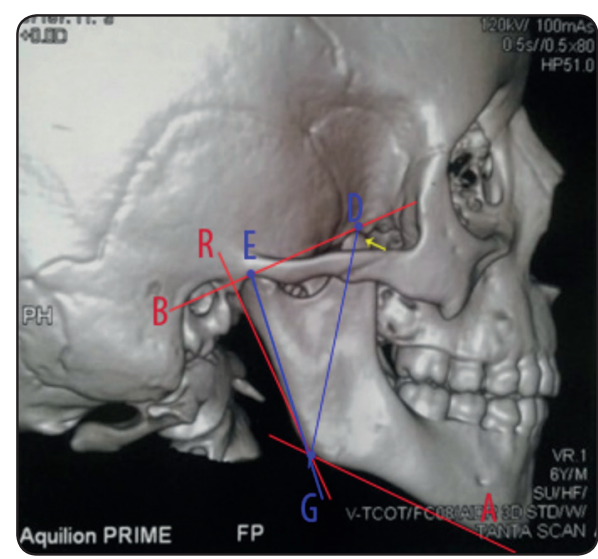

Fig. (I): Lateral projection three dimension computerized tomogram showing elongated coronoid process, lines and points that can be used for determination of CCI. Case no 5 .

2- Line tangent to the apexes of the coronoid process and condyle $(\mathrm{B})$.

3- Line tangent to the outline of the mandibular angle and the posterior part of the head of the condyle. (R).

So, the following points can be determined:

(D). is the point of line (B) with the apex of the coronoid process.
(E). is the point of line (B) with the apex of the head of the condyle.

$(\mathrm{G})$. is the point of intersection of both lines (A) and $(\mathrm{R})$.

After that, the length of coronoid height (GD) and condylar height (GE) was measured.

From the following mathematical formula, the degree of coronoid elongation can be determined.

Coronoid condylar index CCI $=\frac{\mathrm{GD} \text { (coronoid height })}{\mathrm{GE} \text { (condylar height) }}$

Normally, the value of the (CCI) was 1.04 according to Houston (1983). ${ }^{(10)}$ The value above 1.15 points to presence of coronoid hyperplasia. The values of $(\mathrm{CCI})$ between 1.04 to 1.15 may indicate presence of pathology in the coronoid process.

\section{RESULTS}

The results for all 8 patients, who were included in this study, were shown in the following table. (Table1)

Table (1): Showing all the obtained clinical and radiographic examination results for all patients, according to the used clinical and radiographic parameters for evaluation

\begin{tabular}{|c|c|c|c|c|c|c|}
\hline $\begin{array}{c}\text { Case } \\
\text { no }\end{array}$ & $\begin{array}{c}\text { Maximum } \\
\text { range of mouth } \\
\text { opening }(\mathrm{mm})\end{array}$ & $\begin{array}{c}\text { Range of deviation } \\
\text { of mandible toward } \\
\text { affected side }(\mathrm{mm})\end{array}$ & $\begin{array}{c}\text { Presence } \\
\text { of palpable } \\
\text { crepitation }\end{array}$ & $\begin{array}{c}\text { Presence } \\
\text { of audible } \\
\text { grating }\end{array}$ & $\begin{array}{c}\text { Vision of coronoid } \\
\text { process movement in } \\
\text { infra temporal fossa } \\
\text { on opening }\end{array}$ & $\begin{array}{c}\text { DG Ratio } \\
\text { DE }\end{array}$ \\
\hline 1 & 26 & 4 & present & present & Visible & 1.20 \\
\hline 2 & 24 & 3 & present & present & Visible & 1.36 \\
\hline 3 & 27 & 5 & present & Not present & Not Visible & 1.19 \\
\hline 4 & 23 & 5 & Not present & Not present & Visible & 1.24 \\
\hline 5 & 26 & 5 & Not present & Not present & Not Visible & 1.22 \\
\hline 7 & 28 & 6 & Not present & Not present & Not Visible & 1.18 \\
\hline 8 & 25 & Not present & Not present & Present & Visible & 1.21 \\
\hline
\end{tabular}


The obtained clinical results showed the following:

\section{The range of mouth opening:}

The mean of mouth opening for all patients equal $25.3 \mathrm{~mm}$, ranging from 23 to $28 \mathrm{~mm}$.

\section{The range of deviation of the mandible towards the affected side:}

The mean of deviation of the mandible towards the affected side according to Stegenga et. al (1993) was $3.5 \mathrm{~mm}$, ranging from $0 \mathrm{~mm}$ to $6 \mathrm{~mm}$.

\section{Presence of palpable crepitation:-}

Palpable crepitation had been detected only in three cases (case no., 1,2 and 3).

\section{Presence of audible grating:}

Audible grating had been detected only in three cases (case no., 1,2 and 8).

\section{Vision of coronoid process movement in the infratemporal fossa on opening:}

This had been recorded only in four cases (case no., 1,2,4 and 8).

The obtained radiographic results showed the following:

- The ratio between heights of coronoid process to the condylar process i.e. The coronoid condylar index (CCI):

The mean of the CCI to all examined patients was $1.22 \mathrm{~mm}$, ranging from $1.18 \mathrm{~mm}$ to $1.36 \mathrm{~mm}$.

\section{DISCUSSION}

Today, unilateral coronoid hyperplasia is considered as one of many pathologies that can affects considerably on mouth opening with its sequeleas such as causing impaired mastication, disturbances of both mandibular and facial growth and poor oral hygiene. This agreed with Wang et. al (2016), who reported that, unsatisfactory mouth opening may be encountered in some patients with TMJ ankylosis, even when the condylar lesion has been managed properly. ${ }^{(11)}$
In this study, it had been noted that the coronoid process hyperplasia alone led to occurrence of restriction in mouth opening (ranging from 23-28mm). This result agreed with Ilguy et. al (2014), who reported that, coronoid process hyperplasia alone may lead to occurrence of restricted mouth opening in patients without temporomandibular joint ankylosis. ${ }^{(12)}$

In this study, six patients were males and only two patients were females, with an age ranging from 19-28. This agreed with Mcloughlin et. al (1995), who found that, there is male preponderance and post pubertal onset, with the peak age of occurrence in the third decade of life with an average of 24.9 years of age. ${ }^{(3)}$

In the present study, deviation of the mandible towards the affected side had been detected in six patients. This result agreed with Brandt (1943), who reported, occurrence of marked deviation of the jaw towards the affected side in cases of unilateral coronoid hyperplasia. ${ }^{(13)}$

According to the current study, presence of palpable crepitation and audible grating of the temporomandibular joint (TMJ) had been detected only in three cases. This is in acceptance with the result of Yura et. al (2009), who reported presence of some less frequent symptoms such as crepitation or clicking of the temporomandibulal joint in patients with coronoid process hyperplasia. ${ }^{(14)}$

In this study, vision of the movement of the coronoid process in the infratemporal fossa had been detected only in four cases during mouth opening. This agreed with the result of Rowe (1963), who reported that, visible movement of the elongated coronoid process in the infratemporal fossa can be detected during mouth opening particularly in advanced cases. ${ }^{(15)}$

Radiographically, from the computed tomographic examination for both the height of the coronoid and condylar processes i.e. coronoid condylar index (CCI), it had been detected that, the 
mean value was $1.22 \mathrm{~mm}$. This result concide with Stopa et. al (2013), who reported that, if coronoid hyperplasia is present, this proportion may reaches to 1.25 but in normal patients without coronoid hyperplasia, this proportion was close to $1.0 \mathrm{~mm} .{ }^{(16)}$

According to the results of this study computed tomogram is considered as a good diagnostic tool for determination accurately the height of coronoid and condylar processes. This finding was in contrast with Melek et. al (2017), who reported that, cone beam computerized tomogram (CBCT) is superior over the other imaging modalities in determination of bone morphology. ${ }^{(17)}$

\section{CONCLUSION}

From the obtained results of this study, we can conclude that, CCI is considered as simple and rapid method for determination of any discrepancy in both coronoid and condylar processes of the lower jaw, based on the lateral projection of three dimensional computed tomography.

\section{REFERENCES}

1. Langenbeck B.: Angeborene Kleinert der unter kiefer and Langenbeck's Arch, 1953;1:451.

2. Wanyura H, Stopa Z and Zmorzynski M. Bilateral hyperplasia of the mandibular coronoid processes own observation. J. Stoma, (2018);64(1-2):97-105.

3. Mcloughlin PM, Hopper C, and Bowley NB: Hyperplasia of the mandibular coronoid process: an analysis of 31 cases and a review literature. J. Oral \& Maxillfac Surg,(1995);53:250-255.

4. Marra LM: Bilateral coronoid hyperplasia, a developmental defect. J.Oral Surg. Oral Med. Oral Pathol.(1983);55:1013.

5. Azaz B., Zeltser R, and Nitzan DW: Pathoses of coronoid process as a cause of mouth opening restrictions. J.Oral Surg. Oral Med. Oral Pathol. (1994);77:579-584.
6. Tilakaratne WM, Klinikowski MF, and Saku T: Oral submucous fibrosis: review on etiology and pathogenesis. Oral Oncology (2016);42(6):561-568.

7. Tahim AS, Goodson AM, Payne KF and Brenman PA: A review of TMJ. Related papers published in the British Journal of Oral and Maxillofacial Surgery in 2011 and 2012. Br J. Oral \& Maxillofac Surg 2015;53:9-12.

8. Loh SH, Ling SY, Lian CB and Shanmuhasun SP: Bilateral coronoid hyperplasia - a report with a view on its management. J. Oral Rehabilitation. (1997);24:782-787.

9. Stegenga B, Debant LG, De Leau WR and Boering G: Assessment of mandibular function impairment associated with temporomandibular joint osteoarthrosis and internal derangement. J. Orofacial Pain. (1993); 7:183-195.

10. Houston WJ: the analysis of errors in orthodontic measurements. Am.J.Orthod. (1993) May; 83(5):382-390.

11. Wang W.H., Zhang BJ and Lou HA: Temporomandibular joint ankylosis contributing to coronoid process hyperplasia. Int. J. Oral \& Maxillofac Surg. (2016);45:1229-1233.

12. Ilguy M., Kursoglu P and Ilguy D.: Three cases of elongated mandibular coronoid process with different presentations. Ivan J. Radiol.(2014):11;4031.

13. Brand TK: Deformation congenital de l'apophyse coronoid du maxillaire inferieur. Acta Orthop Scand (1943);14:219.

14. Yura S., Ohga N, Ooi K. and Lzumiyama Y.: mandibular coronoid hyperplasia : a case report. J. Craniomaxillofacial Surg. (2009);27:275-279.

15. Rowe NL: Bilateral developmental hyperplasia of the mandibular coronoid process. A report of two cases. Br. J. Oral Surg.(1963);47:90-104.

16. Stopa Z., Wanura H., and Kowalozyk P.: Coronoid condylar index in assessing of mandibular coronoid hyperplasia. Preliminary results. J. advances in Medical Sciences. (2013) Vol.58(2),429-433.

17. Melek Tassoker, Anildidem, Aydin Kabakci, Duygu Akin and Sevgi Sener: Evaluation of mandibular notch, coronoid process and mandibular condyle configurations with cone beam computed tomography. J. Biomedical Res. (2017);28(19):8327-8335. 